\title{
Charitable donations are more responsive to stock market booms than busts
}

\author{
John A. List ${ }^{\mathrm{a}, \mathrm{b}}$, Yana Peysakhovich ${ }^{\mathrm{c}, *}$ \\ a Department of Economics, University of Chicago, 1126 East 59th, Chicago, IL 60637, United States \\ b NBER, United States \\ c Becker Center, Booth School of Business, University of Chicago, 5807 S. Woodlawn Ave, Chicago, IL 60637, United States
}

\section{A R T I C L E I N F O}

\section{Article history:}

Received 17 June 2010

Received in revised form 6 October 2010

Accepted 26 October 2010

Available online 2 November 2010

\section{JEL classification:}

H41

Keywords:

Charitable giving

Private provision of public goods

\section{A B S T R A C T}

This paper examines aggregate time series data on individual charitable donations from 1968 to 2007. We find that changes in individual giving show an asymmetric response to changes in the S\&P 500: individuals are more responsive to stock market upturns than downturns.

(C) 2010 Elsevier B.V. All rights reserved.

\section{Introduction}

Charitable giving remains an important yet insufficiently examined component of human behavior. In 2005 alone, giving was 2.3\% of GDP. Over time, real charitable giving has increased dramatically, and its composition has changed as dramatically. For example, real giving to educational institutions has increased nearly threefold whereas giving to other areas is stagnant.

Economists have not ignored this trend. For years, economists have been working to develop a realistic yet parsimonious model of charitable giving. Initially, individual giving to charity was modeled as a contribution to a public good. Andreoni (1990) incorporated impure altruism, and more recently Della Vigna et al. (2010) incorporated social pressure into the standard model. Empirically, scholars have worked to explore why people give and what models best explain the giving patterns. This literature ranges from the clever studies using naturally-occurring data (see, e.g., Randolph (1995), and Auten et al. (2002)) to the more recent work using field experiments (see, e.g., List and Lucking-Reiley (2002) and Karlan and List (2007)).

Nonetheless, many questions about the nature of charitable giving remain. In this paper, we take a different route than the previous literature: we gather a rich data set to shed light on aggregate patterns of giving. The whole cloth presents interesting insights. For example, growth in total dollars donated has been much stronger than overall growth in the S\&P 500 from 1968 to 2008 . This is due to the cyclical nature of charitable donations, which are quite responsive to macro-

\footnotetext{
* Corresponding author. Tel.: +1 815558 8693; fax: +1 7738343040 . E-mail addresses: jlist@uchicago.edu (J.A. List), yana@uchicago.edu (Y. Peysakhovich).
}

economic fluctuations, but are more sensitive to economic upturns than to economic downturns. These facts combined with other insights discussed below should be useful in furthering our understanding of the economics of charity.

\section{Data summary}

This study draws data from several sources. The Giving USA Foundation publishes and analyzes trends in charitable giving by source of contribution and by type of recipient. They privately provided us with a time-series of giving, broken down by recipient status. Recipients are categorized as religious organizations, educational institutions, human services charities, health charities, pubic and social organizations, and arts and culture. Giving USA's annual estimates are based largely on IRS Form 990 (a tax exemption form that nonprofits complete), but the foundation also econometrically adjusts its estimates based on information from other research institutions. ${ }^{1}$

The data are rich enough to yield interesting plots of charitable giving from 1968 to 2008. Fig. 1 represents one such plot. It shows the dramatic increase in real charitable giving over this time period, which has recently peaked at over $\$ 300$ billion. Within this trend, we see that giving to many sectors has increased dramatically. For example, giving to religious organizations has doubled since the early 1970 's and educational institutions now receive nearly three times the resources from private sources than they received in 1968.

\footnotetext{
${ }^{1}$ Sources of data used in the estimates include the IRS, the Bureau of Economic Analysis, the Council for Aid to Education, the National Council of Churches of Christ, the Foundation Center, the National Center for Charitable Statistics at the Urban Institute, and survey data from the Independent Sector.
} 


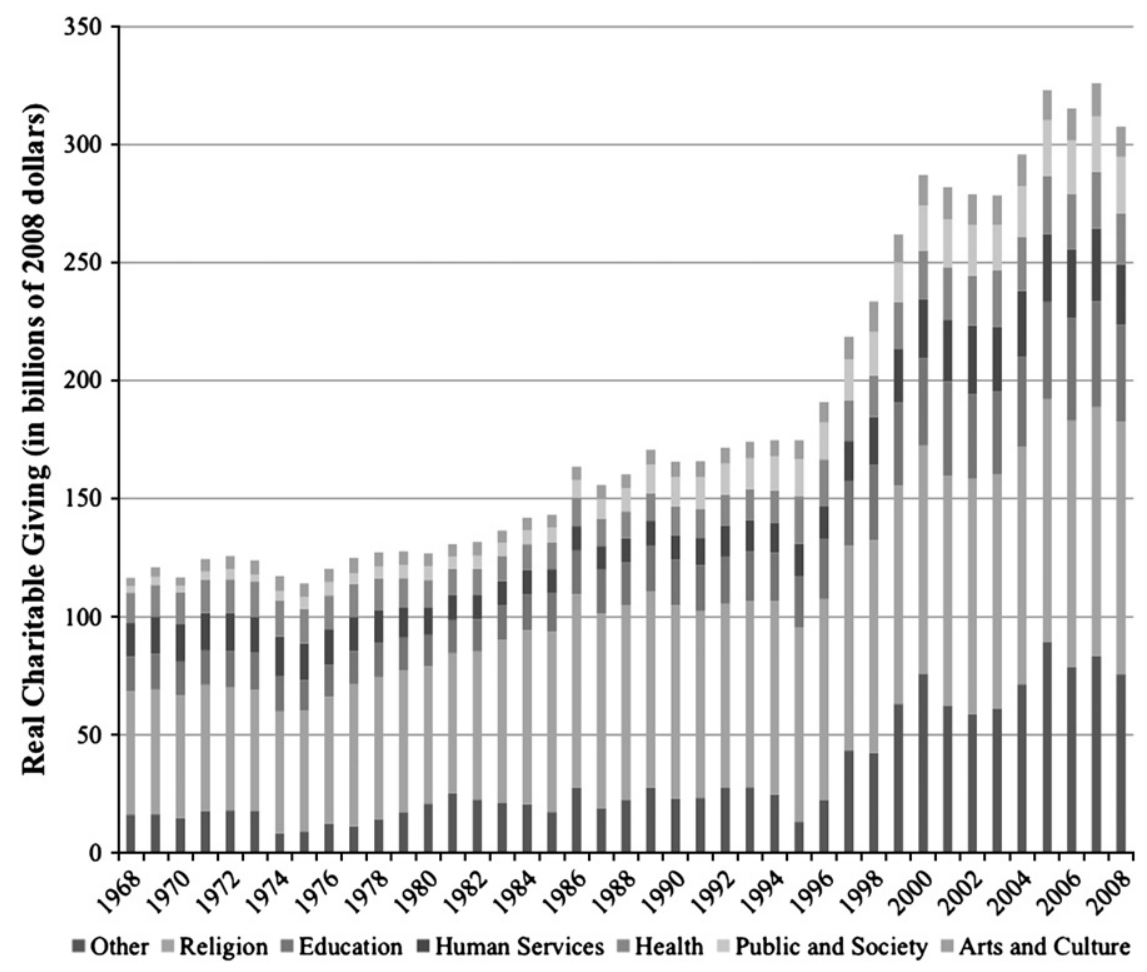

Fig. 1. Decomposition of charitable giving over time.

Throughout this paper, we continue to make use of real, inflationadjusted figures. We use CPI data from the IMF to adjust all nominal values to 2008 dollars. Data on our four economic indicators: GDP, the S\&P 500 index, and unemployment are public. Historical S\&P 500 prices can be found at Yahoo Finance, GDP data at the Bureau of Economic Analysis, and unemployment data at the Bureau of Labor Statistics.

\section{Results}

Table 1 displays the correlation between changes in the variables of interest. The percent change from the previous year for each economic indicator is contained in the rows, and the percent change in each of the components of giving in the columns. Correlations are included for each indicator lagged one year. The table can be read as follows: the correlation between the percentage change in charitable donations from the previous year and percentage change in GDP is 0.4991. The S\&P 500 lagged one year shows the strongest correlation with charitable giving -0.60 . We also see that of all giving components, educational giving has the strongest correlation with our macroeconomic indicators.

To provide further insights into these correlations, we turn to a closer consideration of the relationship between aspects of charitable giving and the S\&P 500 index. In the pure time series, we see in Fig. 2 that the levels of charitable giving and the S\&P 500 have followed a somewhat similar trend over the last thirty years. Interestingly, Fig. 2 shows that charitable giving has increased significantly more in percentage terms than the S\&P 500 from 1968 to 2008.

A scatter plot of percentage changes in charitable giving against percentage changes in the S\&P 500 in the previous year makes these trends clearer, as shown in Fig. 3. The pattern in Fig. 3 shows that changes in charitable giving are closely linked to changes in the S\&P 500. However, such a pattern does not hold for all components of giving. For example, changes in giving to religion are nearly constant when plotted against changes in the S\&P 500, as shown in Fig. 4.

Yet, changes in giving for educational purposes follow a sharp trend around changes in the S\&P 500, as shown in Fig. 5. More specifically, variation in changes in the S\&P 500 can explain approximately $36 \%$ of the variance in changes in total charitable giving. But, changes in the S\&P 500 can explain approximately $51 \%$ of the variance in changes in educational giving, and only $10 \%$ of the variance in religious giving.

Interestingly, despite a fairly consistent response in charitable giving to positive changes in the S\&P 500, the response to negative changes in the S\&P 500 is quite variable and difficult to distinguish from zero. In Fig. 6, a trend line is included with the scatter of lagged percentage changes in the S\&P 500 against percentage changes in charitable giving both on only positive changes in the S\&P 500 and on only negative changes in the S\&P 500.

It is clear that changes in total charitable giving are more responsive to changes in the S\&P 500 in the positive domain than in the negative domain. We note that both intercepts are statistically indistinguishable

Table 1

Correlations between changes in charitable giving and changes in macroeconomic indicators.

\begin{tabular}{|c|c|c|c|c|c|c|c|c|}
\hline & All giving & Religion & Education & Human services & Health & Public and society & Arts and culture & Other \\
\hline GDP & 0.4991 & 0.3427 & 0.5638 & 0.0666 & 0.0728 & -0.0776 & 0.1344 & 0.3325 \\
\hline Lagged GDP & 0.0294 & -0.0163 & 0.205 & 0.1769 & 0.1884 & -0.0334 & 0.1572 & -0.1522 \\
\hline S\&P 500 & 0.4352 & -0.0493 & 0.4271 & 0.2684 & 0.2471 & 0.2136 & 0.2403 & 0.3646 \\
\hline Lagged S\&P 500 & 0.6007 & 0.3101 & 0.7107 & 0.2408 & -0.0143 & -0.1731 & 0.2056 & 0.4278 \\
\hline Unemployment & -0.4143 & -0.2916 & -0.6306 & -0.1389 & -0.1826 & 0.0885 & -0.1383 & -0.1723 \\
\hline Lagged unemployment & 0.0179 & 0.0649 & -0.1258 & -0.1694 & -0.1165 & 0.112 & 0.0461 & 0.121 \\
\hline Consumption expenditures & 0.5121 & 0.4037 & 0.5745 & 0.1512 & 0.1416 & -0.064 & 0.1726 & 0.2777 \\
\hline Lagged consumption expenditures & 0.1402 & 0.1881 & 0.2909 & 0.1938 & 0.2287 & -0.0416 & 0.159 & -0.1134 \\
\hline
\end{tabular}




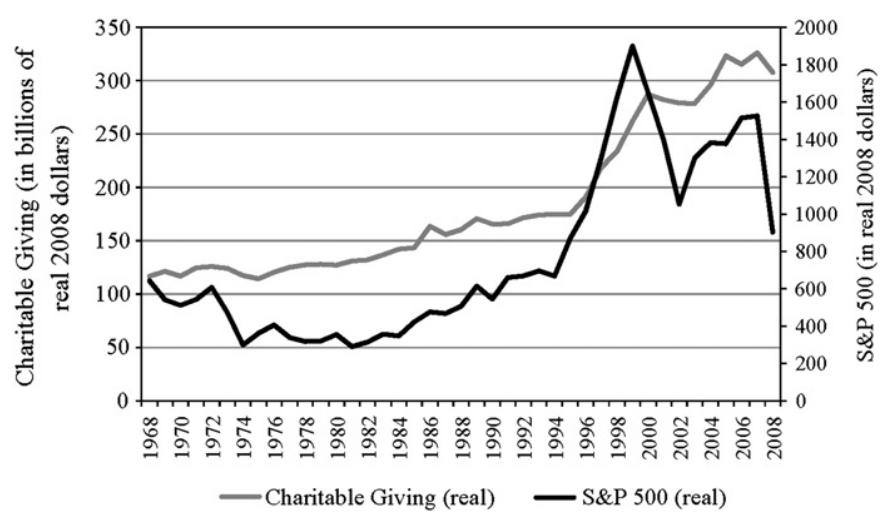

Fig. 2. Real charitable giving and the S\&P 500 index over time.

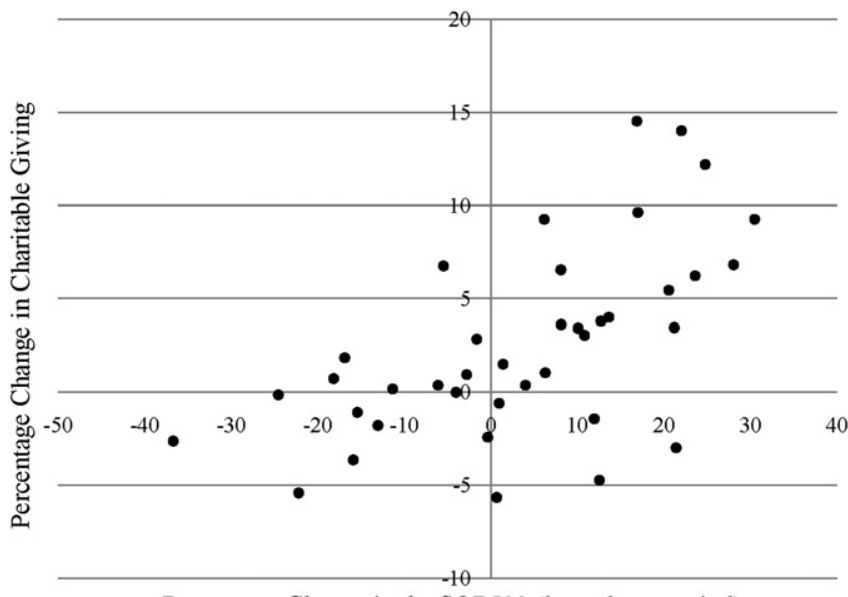

Percentage Change in the S\&P500 (lagged one period)

Fig. 3. Changes in the S\&P 500 vs. changes in charitable giving from 1970 to 2008 .

from zero, and the slope of the line fitted to increases in the S\&P 500 is nearly three times greater than that of the line fitted to decreases in the S\&P 500.

Why might we expect such a trend? If during economic downturns, charitable giving becomes more valuable to recipients of donations (dollars can mean a lot more to a cause), then an income effect that decreases donations to charity may be significantly countered by a substitution effect towards the more valuable commodity of charitable

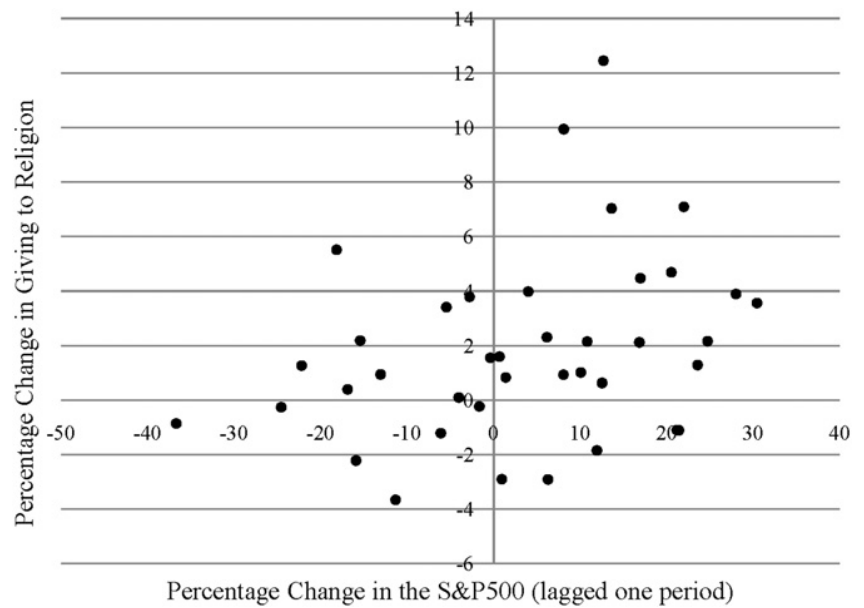

Fig. 4. Changes in the S\&P 500 vs. changes in giving to religious organizations from 1970 to 2008 .

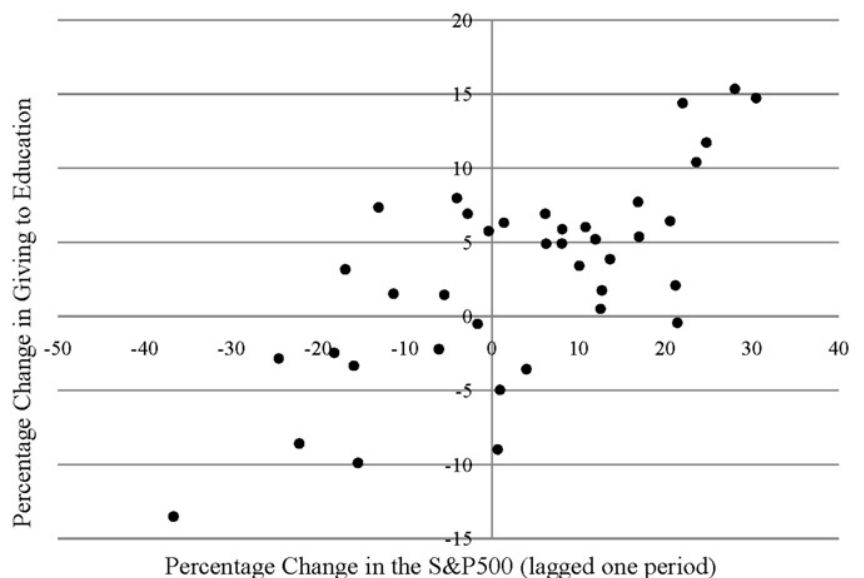

Fig. 5. Changes in the S\&P 500 vs. change in giving to educational organizations from 1970 to 2008 .

giving. This would suggest that the income effect dominates in our positive S\&P region.

An alternative (and perhaps complementary) explanation is that charitable gifts are sticky downwards because social pressure or the desire to maintain the status quo counters the decreases in giving that individuals and foundations may deem necessary. Generally, solicitors for annual gifts know how much a donor gave in the previous year, and seek to improve upon this gift. One fundraising handbook urges readers to remember that "'Secure the gift, renew the gift, upgrade the gift' is the watchword of the annual fund" (Rosso, 2003). Such social pressure to at least maintain past giving levels may cause donors to give more than they would prefer in times of economic hardship. Furthermore, adding to this stickiness is the fact that many large gifts are contracted years in advance, making it difficult to change the trajectory when times become difficult.

Another explanation is that donors are simply prone to giving windfall income. In times that the stock market performs well, the wealthy give away larger portions of their income to charity, though they would not do so if they had foreseen the increase in income. This explanation comes from the theory of mental accounting developed by Thaler (1985). Certainly, these explanations need not operate independently. Likely, substitution toward charitable giving when it becomes more valuable, some social pressure to maintain the status quo, and perhaps mental accounting interact to create the downward-shock insensitive charitable giving that we see emerging from the data.

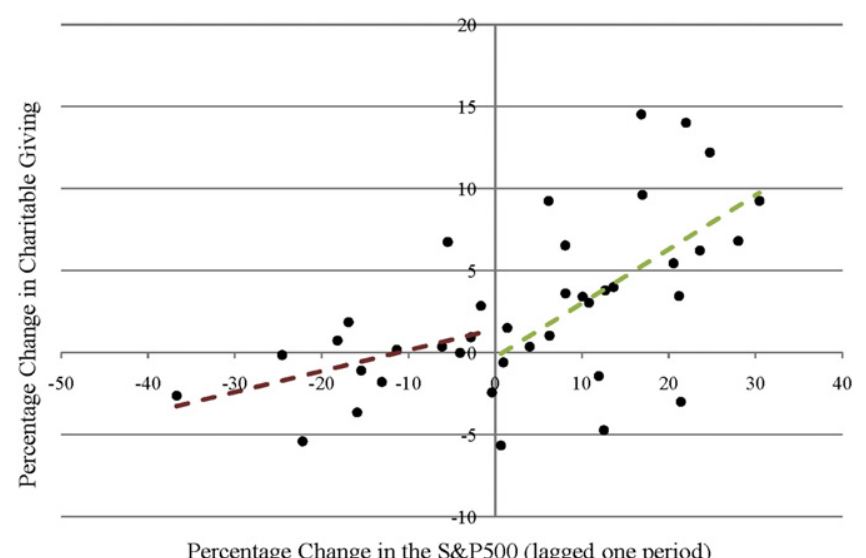

Fig. 6. Changes in the S\&P 500 vs. changes in charitable giving from 1970 to 2009 with trendlines. 


\section{Concluding remarks}

Charitable giving has grown dramatically over the past several decades. In fact, since 1968 growth in charitable gifts exceeds the growth rate of the S\&P 500. An interesting aggregate data pattern is that individual giving is cyclically responsive to macroeconomic fluctuations. Yet, giving is more sensitive to economic upturns than to economic downturns. Further work should parse exactly why this data pattern is observed.

We recognize that money donations do not capture the whole of giving to charitable organizations. Both the donation of money and time can change with the economic climate. When a richer time series on volunteering becomes available, further work should investigate the relationship between volunteering and macroeconomic indicators and complete our snapshot of charitable giving.

\section{Acknowledgments}

We are grateful to Iolanda Palmieri for excellent assistance with the data, and to Trevor Gallen for helpful comments and suggestions. All remaining errors are our own.

\section{References}

Andreoni, J., 1990. Impure altruism and donations to public goods: a theory of warmglow giving. The Economic Journal 100, 464-477.

Auten, G., Sieg, H., Clotfelter, C., 2002. Charitable giving, income, and taxes: an analysis of panel data. The American Economic Review 92, 371-382.

DellaVigna, S., List, J., Malmendier, U., 2010. Testing for Altruism and Social Pressure in Charitable Giving, Working Paper. available at http://www.econ.berkeley.edu/ sdellavi/ wp/charsocpress10-01-28.pdf.

Karlan, D., List, J., 2007. Does price matter in charitable giving? Evidence from a largescale natural field experiment. The American Economic Review 97, 1774-1793.

List, J., Lucking-Reiley, D., 2002. The effects of seed money and refunds on charitable giving: experimental evidence from a university capital campaign. Journal of Political Economy 110, 215-233.

Randolph, W., 1995. Dynamic income, progressive taxes, and the timing of charitable contributions. Journal of Political Economy 103, 709-738.

Rosso, H., 2003. Hank Rosso's achieving excellence in fundraising. John Wiley \& Sons, Inc. Available at http://www.philanthropy.iupui.edu/TheFundRaisingSchool/PrecourseReadings/precourse_ annualfundbuil dingblock.aspx.

Thaler, R., 1985. Mental accounting and consumer choice. Marketing Science 4, 199-214. 